\title{
Gamma Oscillations Coordinate Amygdalo-Rhinal Interactions during Learning
}

\author{
Elizabeth P. Bauer, Rony Paz, and Denis Paré \\ Center for Molecular and Behavioral Neuroscience, Rutgers, The State University of New Jersey, Newark, New Jersey 07102
}

\begin{abstract}
The rhinal cortices contribute to memory formation by integrating and transferring neocortical information to the hippocampus. Rhinal contributions to memory are likely influenced by the amygdala because strong reciprocal connections exist between these structures. In light of previous data showing that oscillations regulate neuronal activity during memory formation and recall, we tested the possibility that coherent oscillations serve to coordinate amygdalo-rhinal activity during learning. To this end, we performed simultaneous extracellular recordings of basolateral amygdala (BLA), perirhinal, and entorhinal activity. We first tested whether there are correlated fluctuations in the power of BLA and rhinal field activity during the waking state. Correlated power fluctuations were most pronounced in the $35-45 \mathrm{~Hz}$ band. Within each structure, firing probability fluctuated rhythmically with the fast oscillations, indicating that they were not volume conducted. To test whether fast oscillations coordinate BLA and rhinal activity during learning, animals were trained on a trace-conditioning task in which a visual conditioned stimulus (CS) predicted a food reward after a delay. The predictive value of the CS was learned gradually over $9 \mathrm{~d}$. As learning progressed, the $35-45 \mathrm{~Hz}$ power increased in the BLA and rhinal cortices, particularly during the late part of the CS and delay. Moreover, the firing of BLA and rhinal neurons became rhythmically entrained by BLA oscillations at that time. Thus, our data suggest that neuronal interactions are coordinated by fast oscillations in the BLA-rhinal network. By telescoping the periods of effective neuronal interactions in short recurring time windows, these fast oscillations may facilitate rhinal interactions and synaptic plasticity.
\end{abstract}

Key words: fast oscillations; $40 \mathrm{~Hz}$; gamma; memory consolidation; conditioning; hippocampus

\section{Introduction}

The rhinal cortices occupy a strategic position among the temporal lobe structures involved in declarative memory. Indeed, most sensory information from the neocortex reaches the hippocampus via the perirhinal and entorhinal cortices (for review, see Burwell and Witter, 2002). The rhinal cortices also form strong reciprocal connections with the basolateral amygdala (BLA) (Krettek and Price, 1977a,b; Room and Groenewegen, 1986; Smith and Paré, 1994), an area implicated in the facilitation of memory by emotions (McGaugh, 2004). Both BLA-rhinal and rhinal-BLA connections arise from glutamatergic neurons that mostly target other principal cells (Smith and Paré, 1994; BrinleyReed et al., 1995; Paré et al., 1995; Farb and Ledoux, 1999; Smith et al., 2000; Pitkänen et al., 2002). The close anatomical ties between the rhinal cortices and BLA suggest that rhinal contributions to memory are likely influenced by the BLA.

Support for the idea that the BLA and rhinal cortices are closely related also comes from physiological studies. For instance, the BLA and rhinal cortices exhibit a similar pattern of

\footnotetext{
Received May 10, 2007; revised June 14, 2007; accepted July 9, 2007.

This work was supported by the National Science Foundation under Grant 0208712 and National Institute of Mental Health Grant R01 MH073610.

Correspondence should be sent to Denis Paré, Center for Molecular and Behavioral Neuroscience, Aidekman Research Center, Rutgers, The State University of New Jersey, 197 University Avenue, Newark, NJ 07102. E-mail: pare@axon.rutgers.edu.

D0I:10.1523/JNEUROSCI.2153-07.2007

Copyright $\odot 2007$ Society for Neuroscience $\quad$ 0270-6474/07/279369-11\$15.00/0
}

spontaneous activity, including slow and delta oscillations in slow-wave sleep and under anesthesia (Paré and Gaudreau, 1996; Collins et al., 2001), as well as theta oscillations during paradoxical sleep (Paré and Gaudreau, 1996) and during emotional arousal (Paré and Collins, 2000; Seidenbecher et al., 2003; Pape et al., 2005).

Although these findings imply that BLA and rhinal functions are intertwined, lesion studies generally emphasize that the amygdala and rhinal cortices contribute to distinct forms of memory. Indeed, rhinal lesions interfere with recognition and associative memory (for review, see Suzuki, 1996). In contrast, amygdala lesions were reported to have little effect on tests probing these functions (Zola-Morgan et al., 1989, 1991; Parker and Gaffan, 1998). Yet other observations support the idea that the amygdala facilitates memory formation via the rhinal cortices in emotionally arousing conditions (Phelps, 2004). For instance, long-term declarative memory for emotionally arousing material is generally better than for neutral events, and this effect is absent in subjects with amygdala lesions (Cahill et al., 1995; Adolphs et al., 1997; Richardson et al., 2004). Moreover, functional imaging studies have reported a high correlation between the amount of amygdala activation at encoding and long-term recall of emotional material (Cahill et al., 1996; Hamann et al., 1999).

In light of these data, the present study was undertaken to examine how the amygdala and rhinal cortices interact in a learning context, focusing on neuronal oscillations. Indeed, evidence suggests that oscillations serve as a mechanism to coordinate ac- 
tivity in different structures during memory formation and recall (Gray and Singer, 1989; Ribary et al., 1991; Lisman and Idiart, 1995; Buzsaki and Draguhn, 2004; Bartos et al., 2007). Thus, we tested the possibility that coherent oscillations serve to coordinate amygdalo-rhinal activity during the acquisition of a traceconditioning task whose acquisition requires interactions between the hippocampus and rhinal cortices (Ryou et al., 2001; Asaka et al., 2002).

\section{Materials and Methods \\ Surgery}

All procedures were approved by the Institutional Animal Care and Use Committee of Rutgers State University, in compliance with the Guide for the Care and Use of Laboratory Animals (Department of Health and Human Services). Three adult cats were preanesthetized with a mixture of ketamine and xylazine (15 and $2 \mathrm{mg} / \mathrm{kg}$, i.m.) and then artificially ventilated with a mixture of ambient air, oxygen, and isoflurane. Atropine $(0.05 \mathrm{mg} / \mathrm{kg}$, i.m.) was administered to prevent secretions. The end-tidal $\mathrm{CO}_{2}$ concentration was maintained at $3.7 \pm$ $0.2 \%$ and the body temperature at $37-38^{\circ} \mathrm{C}$ (with a heating pad). After trepanation and opening of the dura mater, an array of highimpedance microelectrodes was stereotaxically lowered until the electrodes reached the deep layers of the rhinal cortices and the dorsal aspect of the BLA. Then, four screws were cemented to the skull to later fix the cat's head without pain or pressure. Cats were administered penicillin (20,000 UI/kg, i.m.) and an analgesic (Ketofen, $2 \mathrm{mg} / \mathrm{kg}$, s.c.) daily for $3 \mathrm{~d}$ after the surgery. Recording sessions began $8 \mathrm{~d}$ after the surgery.

The array of electrodes was constructed by drilling small holes in a Teflon block and then inserting tungsten microelectrodes into them. The Teflon block was then inserted into a tightly fitting Delrin sleeve, which was cemented to the skull. The lengths of the electrodes were adjusted so that unit recordings could be simultaneously obtained in the BLA and rhinal cortices.

\section{Behavior}

From the very first recording session until the end of the acquisition period, cats were trained on an appetitive trace-conditioning task in which a visual conditioned stimulus (CS) (1.5 s) was followed by a $1.5 \mathrm{~s}$ delay period after which a liquid reward was administered. Trials occurred at random intervals of 30-90 s. The visual CS was a global change in the illumination (from black to white) of a 12 inch liquid crystal display screen placed 1 foot in front of the animals. Detection of the CS did not require the cats to maintain a fixed gaze because the screen encompassed most of the cat's visual field. The liquid reward was pureed Gerber's baby food ( $2 \mathrm{ml} /$ trial). The animals were fed only during recording sessions, and their weight was monitored daily to maintain body weight within $10 \%$ of its initial value. Licking behavior was monitored by means of a switch detecting when the tongue of the animals contacted the receptacle in which the food reward was administered.

\section{Recordings}

Neuronal activity was sampled at $100 \mu \mathrm{m}$ intervals. Each day, the electrodes were lowered to a new recording site, and at least 30 min elapsed before data were acquired, to ensure mechanical stability. The signals picked up by the electrodes $(0.1 \mathrm{~Hz}$ to $20 \mathrm{kHz})$ were observed on an oscilloscope, digitized, and stored on a hard disk. Spike sorting was per- formed off-line using a clustering algorithm based on principal component analysis and $\mathrm{K}$-means.

\section{Histology}

At the end of the experiments, the cats were given an overdose of pentobarbital $(50 \mathrm{mg} / \mathrm{kg}$, i.v.), and the final recording sites were marked with electrolytic lesions $(0.5 \mathrm{~mA}, 10 \mathrm{~s})$. The cats were then perfused transcardially with $500 \mathrm{ml}$ of $0.9 \%$ saline and then $500 \mathrm{ml}$ of fixative (2\% paraformaldehyde and $1 \%$ glutaraldehyde in $0.1 \mathrm{~m}$ phosphate buffer, $\mathrm{pH} 7.4$ ). The brains were later sectioned on a vibrating microtome $(100 \mu \mathrm{m})$ and stained with cresyl violet to verify electrode positions.

\section{Data analysis}

Correlation of power fluctuations. For each recorded channel, field potentials were segmented into 0.5 or $1 \mathrm{~s}$ windows that shifted in steps of 100 ms. Similar results were obtained with both window durations. Fast Fourier transforms (FFTs) were computed for each window. To determine whether power fluctuations at different recording sites were correlated, the power at each frequency for two different channels was correlated with the power of all other frequencies. Correlation coefficients were color coded and plotted in two dimensions with the frequencies of one channel in $y$ and the frequencies of the other in $x$. These correlation plots consistently revealed that power fluctuations at similar frequencies tended to be more correlated than different frequencies. That is, bins along the main diagonal of the correlation matrix had higher correlation coefficients. However, correlation coefficients for the 35-45 Hz range typically seemed higher. To determine whether this difference was significant, we examined only the correlation coefficients within a narrow band (each frequency of one of the channels with the same frequency of the second $\pm 5 \mathrm{~Hz}$ ). We then performed a paired $t$ test between the correlation coefficients at $35-45 \mathrm{~Hz}$ and the correlation coefficients 

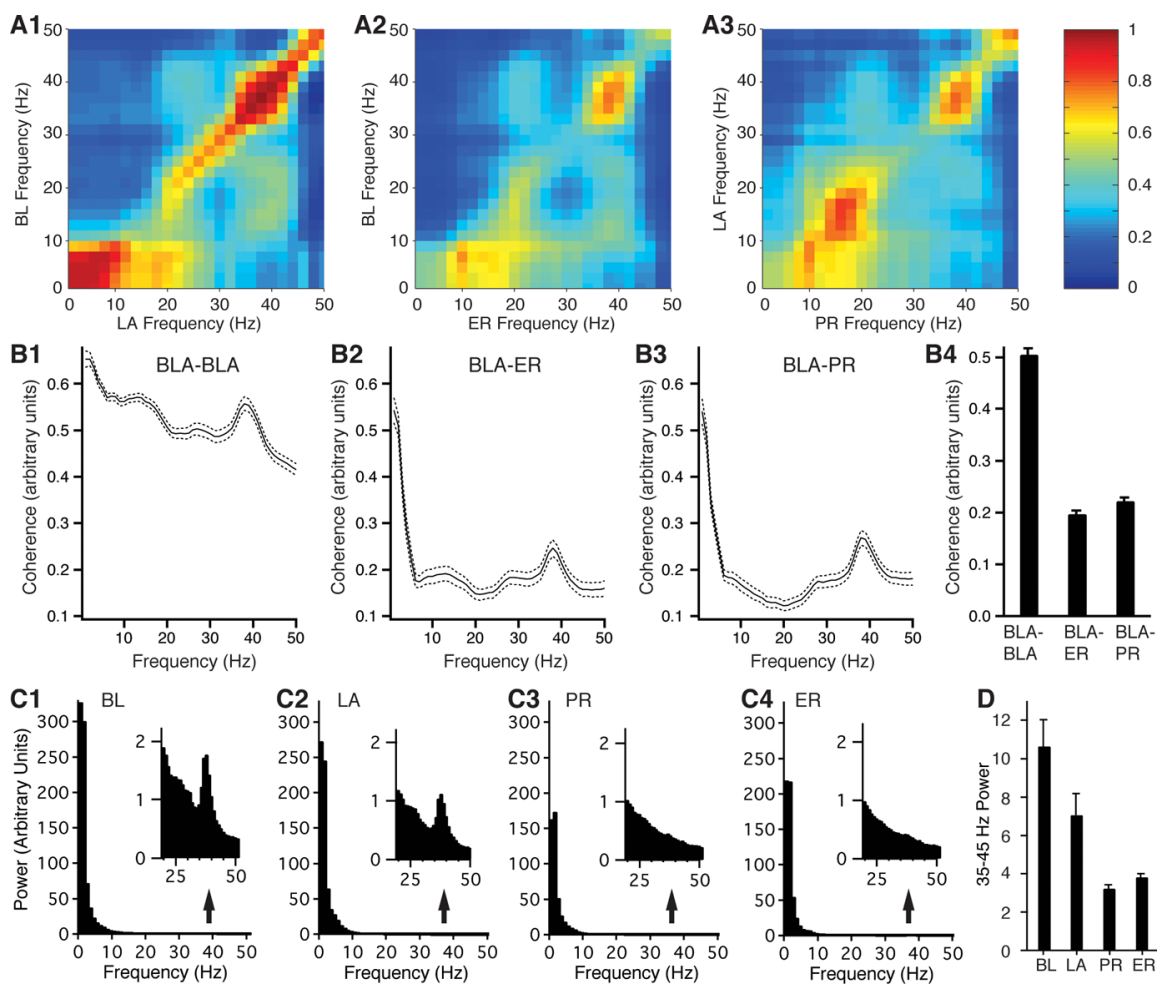

Figure 2. Correlated amygdalo-rhinal power fluctuations in the $35-45 \mathrm{~Hz}$ range. Long periods of spontaneous field potential activity recorded during the waking state were segmented in $1 \mathrm{~s}$ windows. $\boldsymbol{A}$, FFTs were computed for each window, and the power in each frequency was correlated with all others for the following pairs of recording sites: BLA-LA (A1), BLA-ER (A2), and BLA-PR (A3). $\boldsymbol{B}$, Coherence ( $y$-axes) as a function of frequency ( $x$-axes) for recording sites in the BLA (B1), in the BLA and entorhinal cortex (B2), and in the BLA and perirhinal cortex (B3). $\boldsymbol{B} 4$ shows the average coherence values in the $35-45 \mathrm{~Hz}$ range for the same combination of recording sites. C, FFTs of the field potentials recorded in the BL nucleus (C1), LA nucleus (C2), perirhinal cortex (C3), and entorhinal cortex (C4). The insets in $\mathbf{C}$ show a magnified version of the FFTs around the gamma range. D, Power in the $35-45 \mathrm{~Hz}$ range after normalization to total power. PR, Perirhinal cortex; EC, entorhinal cortex.

\section{Results}

\section{Database}

Using an array of high-impedance microelectrodes configured as shown in Figure $1 A$, simultaneous extracellular recordings of BLA, perirhinal, and entorhinal neurons were obtained in three cats. After histological reconstruction of microelectrode tracks (Fig. $1 B-E$ ), it was determined that a total of 115 BLA, 102 perirhinal, and 73 entorhinal neurons were recorded.

\section{Identification of correlated oscillatory activity in the amygdalo-rhinal circuit} We first tested whether there are correlated fluctuations in the power of BLA and rhinal field activity at any frequency in the waking state. These data were obtained between trace-conditioning trials to ensure that the animals were in an attentive state. Local field potentials (LFPs) were segmented into $1 \mathrm{~s}$ windows that shifted in steps of $100 \mathrm{~ms}$. FFTs were computed for each window, and the power at each frequency for one recording site was correlated with the power of all other frequencies at a second recording site. This analysis was performed for all available combinations of recording sites (within the BLA, $n=212$; between the BLA and perirhinal cortex, $n=430$; between the BLA and entorhinal cortex, $n=276$ ).

Figure $2 A$ shows examples of such analyses in which correlation coefficients (color coded) are plotted in two dimenwithin the narrow band of similar frequencies (excluding 35-45 Hz). If there was a significant difference, we determined the direction of the difference: whether the power at $35-45 \mathrm{~Hz}$ was more or less correlated than other frequencies.

To assess the correlation of power fluctuations during trace conditioning, FFTs were computed for the pre-CS, CS, delay, and reward periods for all trials. Then, trial-to-trial power fluctuations were correlated between all pairs of recording sites. Correlation coefficients of power between 35 and $45 \mathrm{~Hz}$ were normalized to pre-CS values.

Computation of rhythmicity indices. We computed perievent histograms of BLA and rhinal unit discharges using the positive peaks of fast field oscillations in the $35-45 \mathrm{~Hz}$ range as temporal references. To this end, field potentials were digitally filtered to isolate the fast oscillations (Chebyshev type II filter, order of 5), and cycles with positive peak $\geq 3$ SD of the overall filtered signal were identified. Then, perievent histograms of unit firing were computed around the positive peaks of the $35-45 \mathrm{~Hz}$ activity. Depending on the analysis, the field activity and units were obtained from the same or different channels. A rhythmicity index (RI) was computed to quantify the strength of the modulation of unit activity by fast oscillations. To compute RIs, we measured the maximal peak to trough difference found within half a cycle of the three central peaks (six measures total), averaged these values, and divided the result by the mean of the entire histogram to normalize for firing rate.

To determine whether unit activity was significantly modulated by the fast oscillations, we constructed 100 perievent histograms of unit discharges using the same spike train but with respect to random times. The original RI was then compared with the distribution of random RIs. It was considered significant if it was higher than $95 \%$ of the randomly generated values. The same approach was used to examine changes in rhythmicity during trace conditioning, except that in this case the analysis was restricted to four time periods: pre-CS, CS, delay, and reward. sions with the frequencies of one channel in $y$ and the frequencies of the other in $x$. Three examples of correlations are shown: within the BLA (Fig. 2A1), between the basolateral (BL) nucleus and entorhinal cortex (Fig. 2A2), and between the lateral (LA) nucleus and perirhinal cortex (Fig. 2A3). These correlation plots consistently revealed that power fluctuations at similar frequencies tended to be more correlated than different frequencies. That is, correlation coefficients along the main diagonal of the matrix tended to have higher values. However, with the exception of frequencies $<4 \mathrm{~Hz}$ (subject to contamination by movement artifacts in waking), correlation coefficients for the 35-45 Hz range typically seemed higher. To determine whether this difference was significant, we restricted our attention to the correlation coefficients within a narrow band (each frequency of one of the channels with the same frequency of the second $\pm 5 \mathrm{~Hz}$ ).

These analyses revealed that power fluctuations in the 35-45 $\mathrm{Hz}$ range were more correlated than at other frequencies ( $t$ tests, $p<0.05)$ in $42 \%$ of all BLA-BLA pairs $(n=212), 40 \%$ of BLAperirhinal pairs $(n=430)$, and $35 \%$ of BLA-entorhinal pairs $(n=276)$. In contrast, when similar analyses were performed for other frequencies $(10-20,20-30$, and $25-35 \mathrm{~Hz})$, the proportions of significant cases ranged between 10 and $23 \%$. This proportion is significantly lower than for $35-45 \mathrm{~Hz}\left(p<0.01, \chi^{2}\right.$ test).

Consistent with this, plots of coherence versus frequency revealed that, of frequencies between 20 and $50 \mathrm{~Hz}$, coherence was maximal in the $35-45 \mathrm{~Hz}$ range for all combinations of recording 
sites (Fig. 2B). However, as shown in Figure $2 C$, computing FFTs on the same data revealed that there was no discrete peak in the range of the fast oscillations in the perirhinal (Fig. 2C3) and entorhinal (Fig. 2C4) cortex, only in the BLA (Fig. $2 C 1, C 2)$. Consistent with this, averaging the $35-45 \mathrm{~Hz}$ power at all available recording sites revealed that fast oscillations were larger in the BLA than in the rhinal cortices whether we considered the absolute 35-45 $\mathrm{Hz}$ power (Fig. 2D) (one-way ANOVA, $F=12.67, p<0.0001$; post hoc $t$ tests, $p<$ 0.004 for all BLA-rhinal comparisons) or divided it by the overall power in all frequencies (data not shown).

To confirm the conclusions derived from the above analyses, the LFPs (Fig. 3, top traces) were digitally filtered (see Materials and Methods) to isolate the fast oscillations and examine how their amplitude fluctuated at the various recording sites (Fig. 3, bottom traces). This analysis was performed in all cats for a few representative epochs, and qualitatively identical results were obtained in all cases. Fast oscillations generally had higher amplitudes in the BLA (Fig. 3, BL, LA1-LA3) than in the rhinal cortices (Fig. 3, PR1PR3, ER1-ER2). Moreover, their amplitude fluctuated markedly over time. In all cats, periods of high-amplitude fast BLA oscillations occurred as spindles, 0.3-1.2 s in duration, that appeared more or less simultaneously at all BLA sites but at irregular intervals. Similarly, marked fluctuations in the amplitude fast rhinal oscillations were seen.

Although the amplitude of BLA and rhinal fast oscillations could sometimes be seen to covary (Fig. 3C), BLA-rhinal coupling was generally less obvious than within the BLA. Consistent with this, the average correlation coefficients of power fluctuations in the $35-45 \mathrm{~Hz}$ range were significantly higher within the BLA $(r=0.53 \pm 0.01 ; n=212)$ than between the BLA and rhinal cortices (BLA-entorhinal, $0.39 \pm 0.01, n=276$; BLA-perirhinal, $0.43 \pm 0.01, n=430)$.

Overall, these results suggest that fast $(35-45 \mathrm{~Hz})$ oscillations represent a dominant EEG rhythm in the amygdalo-rhinal network.

\section{Relationships between theta and gamma activity}

Within each structure, the power of theta activity varied markedly between recording sites (supplemental Fig. $1 A 1$, available at www.jneurosci.org as supplemental material), whether we considered absolute values (supplemental Fig. $1 B$, available at www.jneurosci.org as supplemental material) or normalized the data to total power (supplemental Fig. 1C, available at www. jneurosci.org as supplemental material). However, when we considered all recording sites within each structure, theta and gamma power was weakly correlated (supplemental Fig. $1 \mathrm{~A} 2$, available at www.jneurosci.org as supplemental material). Moreover, al-
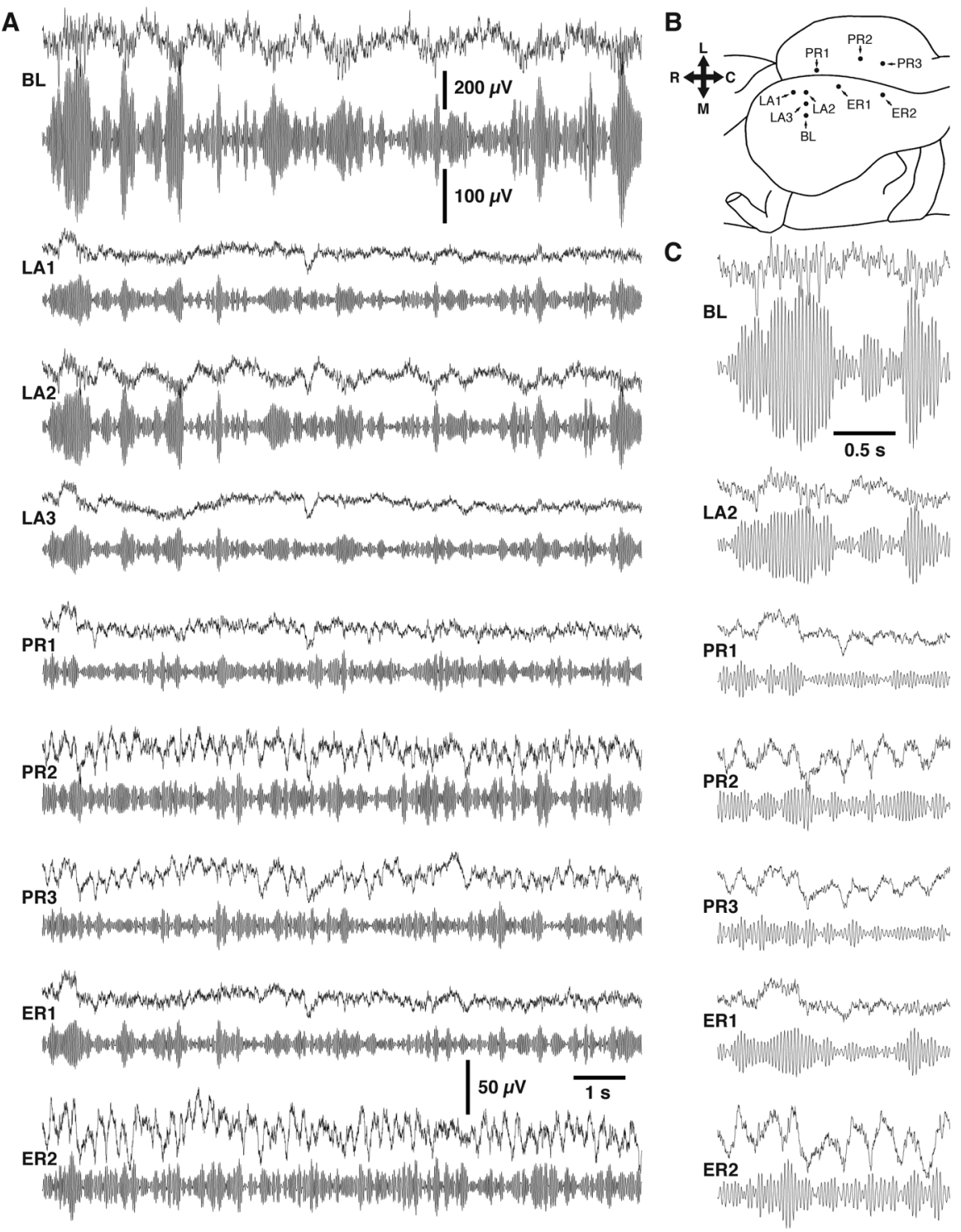

Figure 3. $\quad A-C$, Field potentials recorded simultaneously in the amygdala (BL, LA1-LA3), perirhinal (PR1-PR3), and entorhinal cortex (ER1-ER2) during quiet wakefulness. The location of recording sites is shown in $\boldsymbol{B}$. The field potentials are shown with a slow $(\boldsymbol{A})$ and a fast $(\boldsymbol{C})$ time base. For each recording site, the top trace shows field activity filtered between 0.1 and $300 \mathrm{~Hz}$, whereas the bottom trace was obtained after digital filtering between 35 and $45 \mathrm{~Hz}$. C, Caudal; L, lateral; M, medial; R, rostral.

though gamma power was significantly higher in the BLA than in the rhinal cortices (Fig. 2D), the incidence of recording sites with clear theta peaks in their FFT was significantly lower in the BLA (7\% of 224$)$ than in the perirhinal $(28 \%$ of 224$)$ and entorhinal ( $29 \%$ of 224 ) cortices. Although this suggests that fast amygdalorhinal oscillations have a tenuous relationship to theta activity, it remained possible that, locally in the rhinal cortex, theta and gamma oscillations are related. To explore this possibility, we compared gamma power (normalized to total power) in sites with low versus high theta power (supplemental Fig. $1 D$, available at www.jneurosci.org as supplemental material). In the perirhinal cortex (supplemental Fig. 1D2, available at www. jneurosci.org as supplemental material), gamma power was $56 \%$ higher $(t$ test, $p<0.05)$ in channels with high compared with low theta power. However, this effect was not observed in the entorhinal cortex (supplemental Fig. 1D1, available at www. jneurosci.org as supplemental material) and BLA (supplemental Fig. 1D3, available at www.jneurosci.org as supplemental mate- 
A
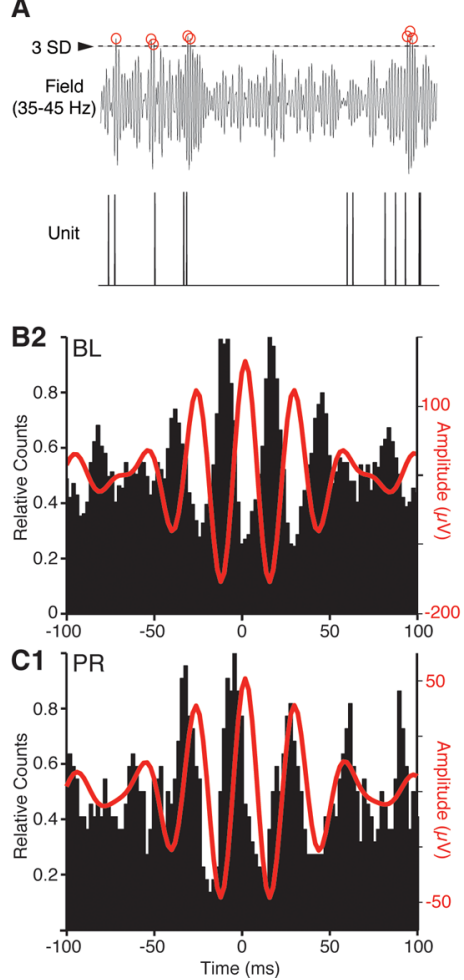

B1

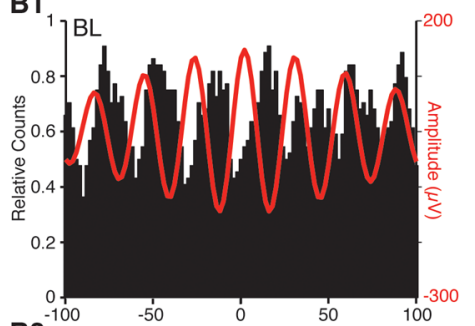

B3 $^{-100}$

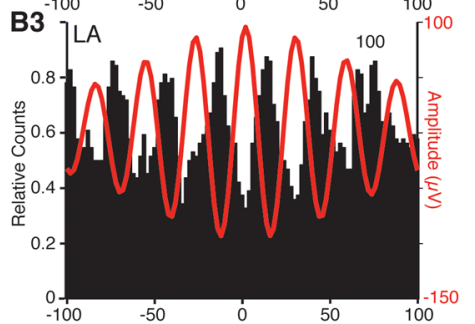

C2 JER

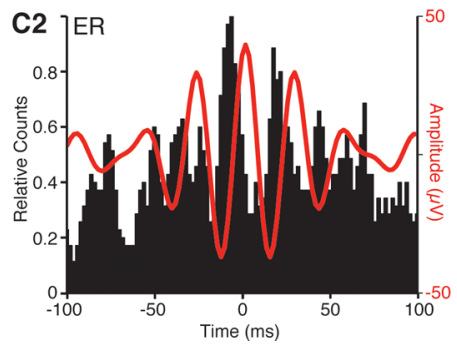

Figure 4. BLA and rhinal neurons fire rhythmically in relation to $35-45 \mathrm{~Hz}$ oscillations. $A$, Method used to test whether unit activity was modulated by the fast oscillations. Local field potentials were digitally filtered ( $35-45 \mathrm{~Hz}$; top trace), and the positive peaks (red circles) of cycles $\geq 3$ SDs of the filtered signal were used as a temporal reference to align unit activity (bottom trace) recorded by the same electrode. $\boldsymbol{B}, \boldsymbol{C}$, Examples of $B L A(\boldsymbol{B})$ and rhinal $(\boldsymbol{C})$ neurons showing statistically significant modulation of firing probability in relation to fast oscillations (assessed by shuffling). $\boldsymbol{D}, \boldsymbol{E}$, Frequency distributions of rhythmicity index (D) and firing peak times $(\boldsymbol{E})$ for BLA (1) and rhinal (2) cells. PR, Perirhinal cortex; EC, entorhinal cortex.

rial) ( $t$ tests, $p>0.05$ ). Another possibility, not probed in the above tests is that moment-to-moment fluctuations in gamma and theta power are related. To examine this possibility, we analyzed spontaneous waking data in $1 \mathrm{~s}$ windows and correlated power fluctuations in the gamma and theta band for each channel. However, correlation coefficients were low (perirhinal, $r=$ $0.16 \pm 0.02$; entorhinal, $r=0.19 \pm 0.02$; BLA, $r=0.08 \pm 0.02$ ).

Thus, although instantaneous fluctuations in theta and gamma power are somewhat related in the rhinal cortices, this is not the case for BLA activity. In light of this, it appears that theta is not a determinant factor in facilitating the emergence of correlated fast BLA-rhinal oscillations.

\section{Relationships between unit activity and fast oscillations}

To determine whether the fast oscillations seen in the LFPs were volume conducted from neighboring structures versus generated locally, we examined whether BLA and rhinal unit activity was modulated by the $35-45 \mathrm{~Hz}$ oscillations. To this end, we constructed perievent histograms of unit activity around the positive peaks of the fast oscillations recorded by the same microelectrode as used for the unit activity. First, the fast oscillations were isolated by digitally filtering the LFPs, and cycles with positive peak greater than or equal to the average plus 3 SDs of the overall filtered signal were identified (Fig. $4 \mathrm{~A}$ ). Similar results were obtained with peaks $\geq 2$ or 2.5 SDs. Then, histograms of spike firing for each cell were constructed around the positive peaks of the fast oscillations picked up by the same electrode as the unit activity (Fig. $4 B, C$ ). Figure 4 shows examples of such perievent histograms for BLA (Fig. $4 B$ ) and rhinal (Fig. 4C) neurons. As evi-
D1 Amygdala

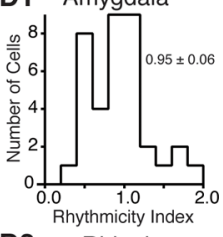

D2
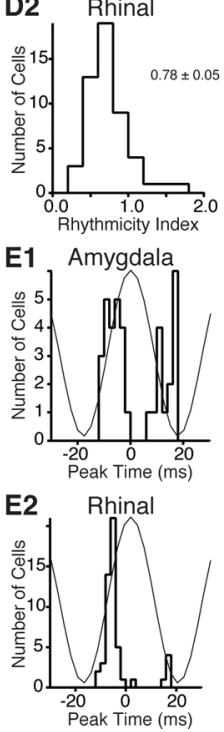

denced in these examples, modulation of unit activity by fast oscillations was observed frequently, indicating that the fast oscillations seen in the BLA and rhinal cortices were not volume conducted.

To compare the modulation of unit activity by fast oscillations in the various regions, we computed an RI for each cell. The RI was obtained by averaging the difference in spike counts between the three center peaks and troughs of the perievent histograms (for details, see Materials and Methods) and dividing the result by the average of the entire histogram to normalize for variations in firing rates. Statistical significance of the RI was tested by recomputing the perievent histograms after shuffling the peak times, repeating this process 100 times. The actual RI was considered significant if it was higher than $95 \%$ of the randomly generated RIs.

Using this approach, it was determined that RIs were significant in 44,43 , and $46 \%$ of BLA, perirhinal, and entorhinal neurons, respectively. Figure $4 D$ shows the distribution of RIs for all BLA (Fig. 4D1) and rhinal (Fig. 4D2) neurons with significant RIs. The RIs of BLA neurons (0.95 \pm $0.06)$ were significantly higher than that of rhinal neurons $(0.78 \pm 0.05, t$ test, $p<$ 0.03; Wilcoxon's rank sum test, $p<0.01$ ), yet the timing of the largest peaks with respect to the fact oscillations was similar in the BLA and rhinal cortices. This point is addressed in Figure $4 E$ showing the distribution of peak times for BLA (Fig. 4E1) and rhinal (Fig. 4E2) neurons with significant RIs. In both cases, most of the peaks occurred during the rising positive phase of the fast oscillation (Fig. 4E1,E2). However, there was a smaller group of cells, significantly more important in the BLA ( $\chi^{2}$ test, $p<0.05$ ), with peak times coinciding with the falling positive phase or negative peak of the fast oscillations (Fig. $4 E 1$ ). The proportion of BL neurons with histogram peaks centered on the negative peak of the fast oscillation $(21 \%)$ was significantly higher than seen among LA neurons $\left(4 \% ; \chi^{2}\right.$ test, $p<$ $0.05)$. Coupled to the higher power of fast oscillations in the $\mathrm{BL}$ nucleus (Fig. 2D), this observation suggests that the BL nucleus may play a particularly important role in generating fast oscillations in this network.

To determine whether fast oscillations are associated with changes in firing rates, we compared the firing rates of BLA, perirhinal, and entorhinal neurons in periods of high versus low gamma power. Within each structure, there was heterogeneity in this respect, with some cells increasing, others decreasing or not changing their firing rates when gamma power increased. In keeping with this, overall differences in firing rates between periods of high versus low gamma power did not reach significance (BLA, $2.09 \pm 0.28$ and $2.07 \pm 0.29 \mathrm{~Hz}$; perirhinal, $3.51 \pm 0.37$ and $3.45 \pm 0.37 \mathrm{~Hz}$; entorhinal, $2.95 \pm 0.35$ and $2.6 \pm 0.29 \mathrm{~Hz}$; $t$ tests, $p>0.05)$.

Overall, these data indicate that, within the BLA and rhinal cortices, fast field potential oscillations are associated with rhythmic modulations of firing probability. Considering the high coherence of BLA and rhinal gamma oscillations and in light of the 
involvement of these structures in memory, we next tested whether neuronal interactions at the gamma frequency coordinate amygdalo-rhinal interactions during learning.

Fast oscillatory activity during learning To investigate whether amygdalo-rhinal interactions are modulated by fast oscillations in a learning context, we trained three cats on an appetitive traceconditioning task whose acquisition was shown previously to depend on interactions between the hippocampus, rhinal cortices, and BLA (Ryou et al., 2001; Asaka et al., 2002; Paz et al., 2006).

The trace-conditioning paradigm consisted of the presentation of a $1.5 \mathrm{~s}$ visual CS (global change in the illumination of a computer screen) followed by a delay period of equal duration after which a liquid food reward was delivered (Fig. 5A). Progression of learning on this task was monitored by analyzing the rate of anticipatory licking (licking occurring after the CS but before reward delivery) (Fig. 5B). All animals considered individually or as a group showed a rapid initial learning phase that could be observed as early as training days $2-3$, followed by a protracted period of slower improvements that extended up to training days 5-9 (ANOVA of trials over sessions, $p<0.05$ for all animals). Overall, this suggests that, although memory for the predictive value of the CS for reward delivery is formed as early as the second training session, it is then gradually strengthened over a period of several days. Based on this evidence, we separated the training sessions into an early and a late phase (training days $1-3$ vs 7-9) (Fig. 5B).

To test whether the amplitude of fast oscillations varied as a function of the learning phase, the data obtained during trace-conditioning trials was segmented in 500 ms windows, FFTs were computed for each window, and the 35-45 $\mathrm{Hz}$ power was plotted after normalization to the total power in all frequencies (Fig. $5 C, D$ ). This analysis revealed that the main difference between early (Fig. 5C) versus late (Fig. $5 D$ ) training days occurred in relation to the late part of the CS and delay. Indeed, whereas no change in $35-45 \mathrm{~Hz}$ power occurred in relation to the CS and delay at early stages of learning (Fig. 5C), a large (up to 19\%) and sustained increase in the power of fast oscillations was seen at late stages of training (Fig. 5D) in the BLA and rhinal cortices $\left(p<0.01, \chi^{2}\right.$ test). This delayassociated rise in the power of fast oscillations actually began during the late part of the CS and was the only consistent difference to be observed between early versus late days of training across the three structures.

Not only was there a delay-related increase in the power of fast oscillations at late stages of learning (Fig. 5D), but trial-to-trial
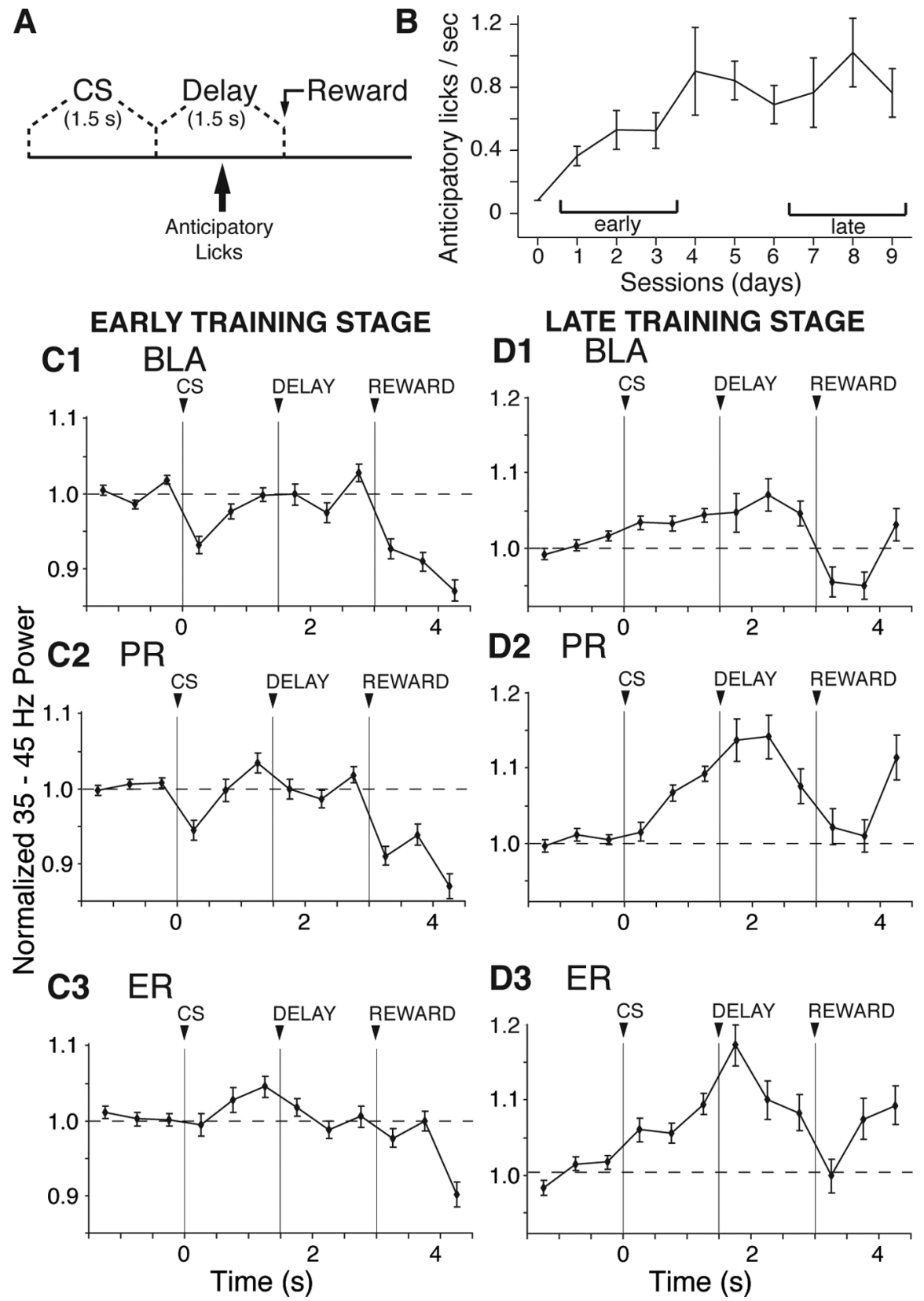

D3 ER

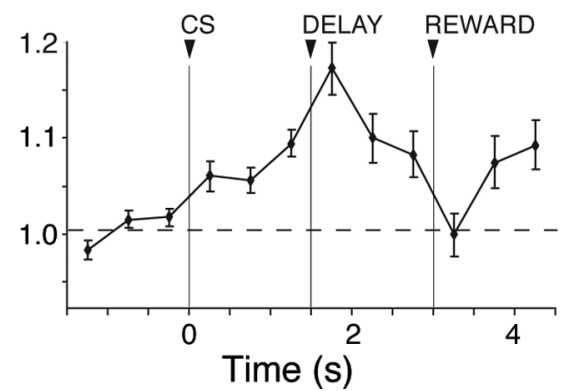

Figure 5. Acquisition of a trace-conditioning task is paralleled by modifications of $35-45 \mathrm{~Hz}$ power in the amygdala and rhinal cortices. $\boldsymbol{A}$, Trace-conditioning task. Timing of the visual $C S$, delay period, and reward delivery. $\boldsymbol{B}$, Graph plotting the number of anticipatory licks ( $y$-axis) as a function of training sessions ( $x$-axis). The graphs in $\boldsymbol{C}$ and $\boldsymbol{D}$ plot normalized $35-45 \mathrm{~Hz}$ power (D1-D3) stages of learning. Data normalization was achieved by dividing the $35-45 \mathrm{~Hz}$ power by the total power. PR, Perirhinal cortex; EC, entorhinal cortex.

fluctuations in $35-45 \mathrm{~Hz}$ power at the various recording sites were also more strongly correlated than at early stages of training during the delay (Fig. 6).

To study this point, FFTs were computed for the pre-CS, CS, delay, and reward periods for all trials. Then, trial-to-trial power fluctuations of fast oscillations were correlated between all pairs of available BLA recording sites (early, $n=59$; late, $n=67$ ), BLA and perirhinal sites (early, $n=46$; late, $n=101$ ), as well as BLA and entorhinal sites (early, $n=97$; late, $n=85$ ). Correlation coefficients were normalized to pre-CS values.

The pre-CS values for BLA-BLA correlations at early versus late stages of learning were statistically indistinguishable (early, 

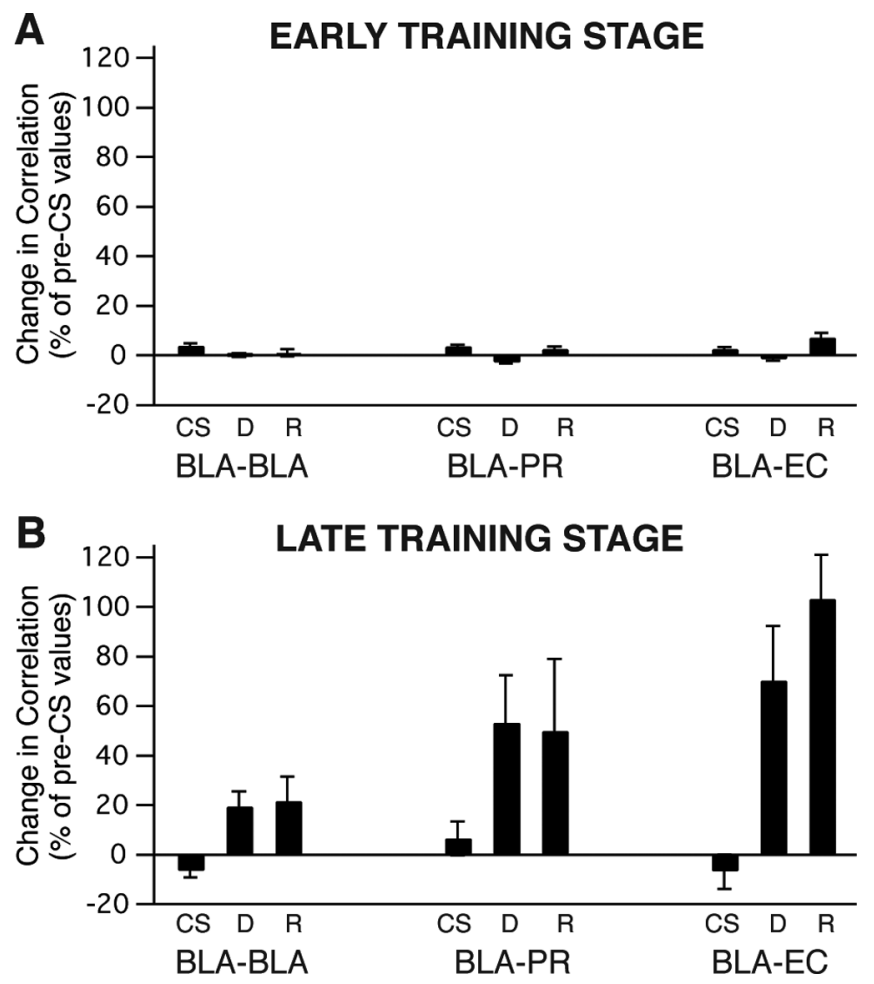

Figure 6. $A, B$, Change in correlated $35-45 \mathrm{~Hz}$ power fluctuations in the BLA and rhinal cortices observed at early $(\boldsymbol{A})$ and late $(\boldsymbol{B})$ stages of learning. Percentage change in correlation coefficients (normalized to pre-CS values) for $35-45 \mathrm{~Hz}$ power fluctuations in field potentials recorded simultaneously in the BLA (left), BLA and perirhinal cortex (middle), or BLA and entorhinal cortex (right) in relation to the $C S$, delay (D), or reward (R).

$0.50 \pm 0.03$; late, $0.56 \pm 0.03 ; t$ test, $p=0.1$ ). In contrast, the $r$ values of the pre-CS period were significantly higher for the late compared with the early learning stages for both BLA-perirhinal (early, $0.31 \pm 0.01$; late, $0.39 \pm 0.02$ ) and BLA-entorhinal (early, $0.24 \pm 0.02$; late, $0.36 \pm 0.02)$ correlations ( $t$ tests, $p<0.01$ ). These higher pre-CS correlations suggest that, despite the variable duration of inter-CS intervals, the animals anticipated the $\mathrm{CS}$ at late stages of training but not initially.

Compared with the early training phase, there was a large increase in the correlation of $35-45 \mathrm{~Hz}$ power fluctuations at late stages of learning in relation to the delay and reward for all combination of recording sites ( $t$ tests, $p<0.05$ ). For an example of delay-related increase in the correlation of trial-to-trial power fluctuations at $35-45 \mathrm{~Hz}$ at late stages of learning, see Figure 7.

To determine whether this was reflected in the modulation of unit activity by $35-45 \mathrm{~Hz}$ oscillations, we digitally filtered the LFPs of BLA channels between 35 and $45 \mathrm{~Hz}$ and examined unit firing of BLA, perirhinal, and entorhinal units with respect to fast BLA oscillations. Perievent histograms of unit activity were constructed and RIs computed as described above (see Fig. 4 and associated text). The RIs measured during the CS, delay, and reward period were then normalized to pre-CS values (supplemental Table S1, available at www.jneurosci.org as supplemental material).

As shown in the bar graphs of Figure $8 A$, during the early phase of training, RIs increased by $5-33 \%$ during the various phases of the conditioning trials compared with the pre-CS period. These changes were statistically significant for all combinations of recording sites (paired $t$ tests, $p>0.05$ ) with the exception of reward-related activity between the BLA and rhinal cortices. Consistent with the $35-45 \mathrm{~Hz}$ power analysis described above, the only significant differences in RIs between the early and late phase of training was observed during the delay ( $t$ tests, $p<0.05)$ when all pairs of recording sites showed a large increase in RIs (range, 60-250\%) (Fig. 8B). Similar results were obtained when this analysis was performed with rhinal gamma (supplemental Fig. 2, Table 1, available at www.jneurosci.org as supplemental material) rather than BLA gamma.

The delay-related increase in rhythmicity seen at late stages of learning is evident in the perievent histograms of Figure $8 C-E$ in which the modulation of unit activity by the fast BLA oscillation is shown for the pre-CS period and delay period, late in training. Overall, these results indicate that, within all three structures, neuronal firing became rhythmically entrained by the fast BLA oscillations during the delay phase when the BLA rhinal cortices and hippocampus are thought to cooperate.

\section{Discussion}

The present study examined the role of fast $(35-45 \mathrm{~Hz})$ oscillations in coordinating amygdalo-rhinal interactions. The interest of this issue stems from recent findings suggesting that synchronized BLA activity facilitates rhinal interactions in a learning context (Paz et al., 2006) and previous work implicating fast oscillations in higher brain functions (Gray and Singer, 1989; Ribary et al., 1991; Lisman and Idiart, 1995; Buzsaki and Draguhn, 2004; Bartos et al., 2007). Our results indicate that there are correlated fast field oscillations in the BLA and rhinal cortices during attentive waking, that these oscillations are associated with a rhythmic modulation in the firing probability of BLA and rhinal neurons, and that their power increases as a result of learning in an appetitive traceconditioning task. The significance of these observations for amygdalo-rhinal interactions is considered below.

Fast oscillations: ubiquity and underlying mechanisms Fast oscillations in the $40 \mathrm{~Hz}$ range are ubiquitous in the brain (Steriade, 1997; Traub et al., 1998). Indeed, in a number of species, they have been observed to occur spontaneously in a various cortical and subcortical sites, including the prepyriform cortex (Freeman, 1959), neocortex (Eckhorn et al., 1988; Gray and Singer, 1989; Cardin et al., 2005), hippocampus (Bragin et al., 1995), rhinal cortices (Charpak et al., 1995; Dickson et al., 2003), thalamus (Steriade et al., 1991, 1996), and striatum (Courtemanche et al., 2003). Fast oscillations also occur in a variety of behavioral states, from anesthesia and slow-wave sleep (Steriade et al., 1996), to sensory processing (Eckhorn et al., 1988; Gray and Singer, 1989) and attentive waking (Montaron et al., 1982; Murthy and Fetz, 1992; Buschman and Miller, 2007). As a result of these latter observations, it was proposed that fast oscillations play a critical role in cognitive, perceptual, and attentional processes (Koch and Crick, 1991; Llinás and Ribary, 1992; Singer and Gray, 1995; Gray, 1999).

In the neocortex and hippocampus, fast oscillations emerge from interactions between the intrinsic membrane properties (Llinás et al., 1991; Steriade et al., 1991, 1996; Gray and McCormick, 1996; Traub et al., 1996) and connections of constitutive neurons (for review, see Traub et al., 1998). Local inhibitory interneurons play a particularly important role in synchronizing fast oscillations among large sets of principal cells (Buzsáki and Chrobak, 1995; Cobb et al., 1995; Traub et al., 1996; Buhl et al., 1998; Fisahn et al., 1998; Tamás et al., 2000) (for review, see Bartos et al., 2007). This results from the fact that interneurons are coupled by chemical synapses (Kisvárday et al., 1993; Cobb et al., 1997; Tamás et al., 1998) and gap junctions (Galarreta and 
Hestrin, 1999; Gibson et al., 1999). Consequently, in conditions of afferent excitation, interneurons would generate synchronized $\mathrm{GABA}_{\mathrm{A}}$ IPSPs in thousands of principal cells, thus entraining them to fire preferentially on the decaying phase of IPSPs.

In addition, fast oscillations have been reported to synchronize distant neurons in some circumstances. For instance, magnetoencephalographic recordings have revealed that there are spontaneous fast oscillations over the entire cortex in humans with a phase lag of $\sim 12 \mathrm{~ms}$ between the rostral and caudal pole of the brain (Ribary et al., 1991; Llinas and Ribary, 1992). Similarly, presentation of liminal somatosensory stimuli produces a synchronization of prefrontal and parietal fast oscillations when subjects detect the stimuli but not when they remained unregistered (Palva et al., 2005).

\section{Generation of fast oscillations in the amygdalo-rhinal network}

Although in vitro studies indicate that the rhinal cortices can generate fast oscillations autonomously (Cunningham et al., 2004), our results suggest that, in an intact network, in emotionally arousing conditions, amygdala inputs may play a critical role in promoting fast oscillatory activity. This contention is based on the following findings: (1) the BLA sends robust glutamatergic projections to the rhinal cortices (for review, see Pitkänen, 2000), (2) the power of fast oscillations was significantly higher in the BLA than in the rhinal cortices, and (3) the modulation of unit activity by fast oscillations was stronger in the BLA than in the rhinal cortices.

So far, relatively little work has been performed on the cellular mechanisms underlying fast oscillations in the BLA. However, several factors suggest that they are similar to those documented in the neocortex and hippocampus. Indeed, the cellular composition of the BLA is reminiscent of cortex, consisting of a majority of glutamatergic principal neurons and an heterogeneous class of inhibitory interneurons (for review, see McDonald, 1992). Moreover, the electroresponsive properties of principal and localcircuit cells of the BLA and cortex are similar (Paré et al., 2003; Sah et al., 2003). As in cortex, principal cells are interconnected with other principal cells and interneurons (Smith and Paré, 1994; Smith et al., 2000; Muller et al., 2006, 2007). Moreover, parvalbumin-expressing interneurons of the BLA form chemical as well as electrical synapses with each other (Muller et al., 2005; Woodruff and Sah, 2007). Last, application of the gap junction blocker carbenoxolone was reported to disrupt fast oscillatory activity induced by application of nanomolar concentrations of kainic acid in brain amygdala slices kept in vitro (Sinfield and Collins, 2006).

At present, it is unclear whether fast BLA oscillations are paced by rhythmically active inputs, extrinsic to the BLA, or whether the rhythm emerges out of intrinsic synaptic interactions between principal and local-circuit neurons of the BLA. In support of the first possibility, some tracing studies suggest that the BLA receives inputs from the prepyriform cortex (Russchen, 1982; McDonald,
1998 ) in which oscillations in the $40 \mathrm{~Hz}$ range have been described (Freeman, 1959). However, these projections are rather sparse. An important question to be addressed in the future will be to determine whether prepyriform and BLA oscillations are related.

\section{Learning-related changes in fast amygdala and rhinal oscillations}

In a previous study, using the same behavioral task and correlative analyses of BLA and rhinal firing, we observed that BLA activity facilitated rhinal interactions (Paz et al., 2006). At early but not late stages of training, this effect was seen in relation to reward delivery. In contrast, at late stages of training, this effect occurred in relation to the delay but not the reward. Analysis of the underlying mechanisms revealed that both the early (reward-related) and the late (delay-related) effects resulted from an increased synchrony in the activity of BLA neurons (Paz et al., 2006). However, the mechanisms underlying this enhanced synchrony remained unclear. The present study tested whether fast oscillations contributed to synchronize the activity of BLA and rhinal cells in the trace conditioning task.

Consistent with this possibility, we observed that at late (but not early) stages of learning, the power and correlation of fast BLA and rhinal oscillations increased during the delay. However, no reward-related changes in correlated fast oscillatory activity were seen in relation to the reward at either stages of learning. Thus, these results suggest that, although fast oscillatory activity may contribute to enhance BLA-rhinal interactions, they are only part of the story. The reward-related effect seen at early stages of learning remains unexplained. 

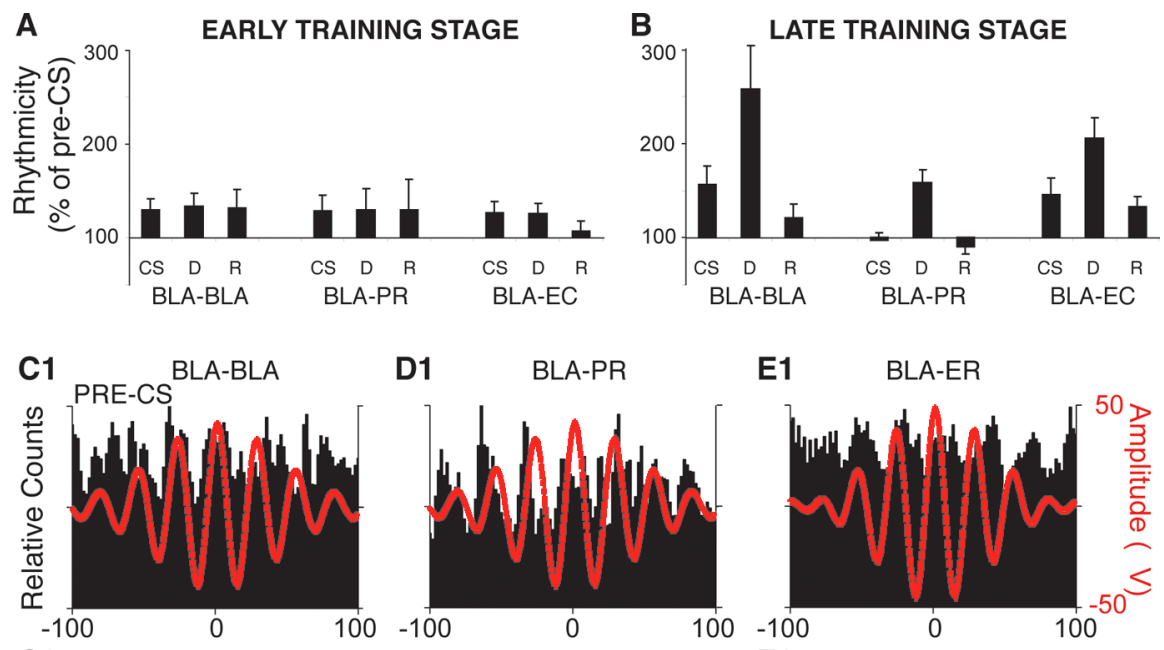

D1

BLA-PR
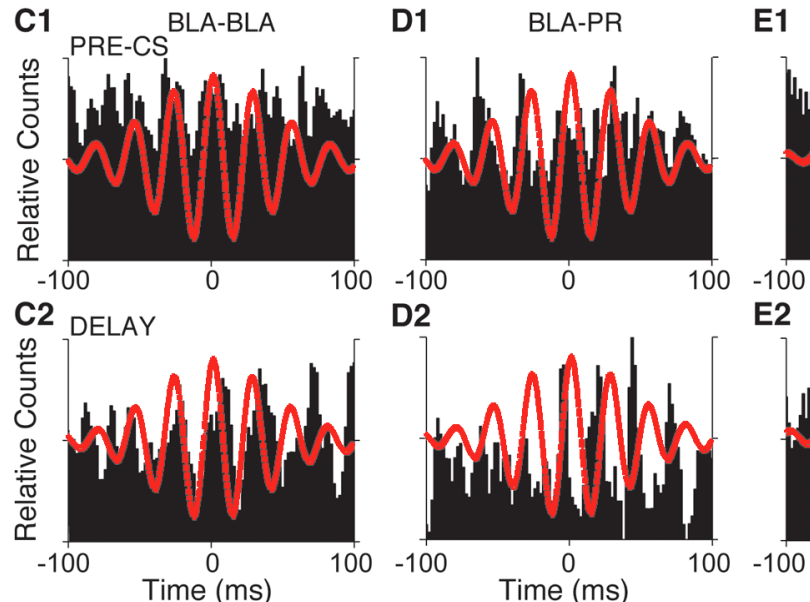

D2
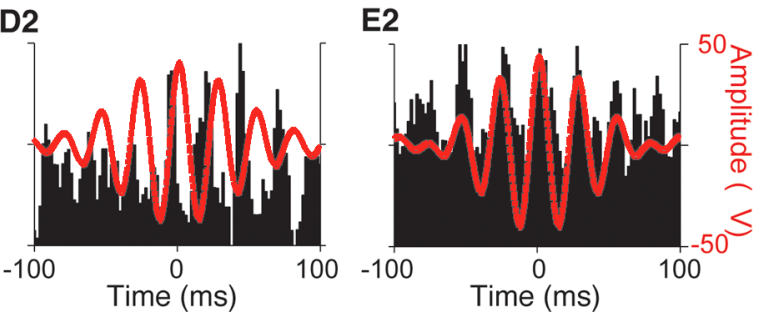

Figure 8. Unit activity parallels learning-related changes in $35-45 \mathrm{~Hz}$ correlated power fluctuations at late stages of training. $A, B$, Average rhythmicity index for BLA, perirhinal, and entorhinal firing in relation to $35-45 \mathrm{~Hz}$ BLA oscillations, as explained in the legend of Figure 4. The data are expressed as percentage of pre- $C S$ values and is shown for the data obtained at early $(\boldsymbol{A})$ and late $(\boldsymbol{B})$ stages of learning. $\boldsymbol{C}-\boldsymbol{E}$, Examples of perievent histograms of unit activity in relation to fast BLA oscillations recorded before the CS (1) or during the delay (2) at late stages of learning. $\mathbf{C}-\boldsymbol{E}$, respectively, show BLA units in relation to fast BLA oscillations $(\boldsymbol{C})$, perirhinal units in relation to fast BLA oscillations (D), or entorhinal units in relation to fast BLA oscillations (E). D, Delay; $R$, reward; PR, perirhinal cortex; EC, entorhinal cortex.

Functional significance of fast amygdalo-rhinal oscillations At a neuronal level, the entrainment of BLA and rhinal activity by fast oscillations likely facilitates interactions between these structures. Indeed, fast oscillations telescope the periods of neuronal interactions in short recurring time windows, when the membrane potential and electrotonic structure of the cells favor the genesis of orthodromic spikes. Considering the essential role that coincident neuronal activity is believed to play in synaptic plasticity (Bliss and Collingridge, 1993; Malenka and Nicoll, 1993) and the involvement of the amygdala and rhinal cortices in memory (Zola-Morgan et al., 1989; Cahill et al., 1996; Suzuki, 1996; Fanselow and LeDoux, 1999), the presence of coherent fast oscillations in the BLA and rhinal cortices might thus create network conditions that promote memory formation.

Evidence that precise temporal coordination is a critical aspect of amygdalo-rhinal interactions comes from analyses of conduction times from BLA neurons to the rhinal cortices. Indeed, achieving synchrony in the amygdalo-rhinal network presents special challenges because the amygdala is located at the rostral pole of the temporal lobe, whereas the rhinal cortices extend $>1$ $\mathrm{cm}$ rostrocaudally. However, it was found that the conduction of times of BLA neurons to the rhinal cortices is constant despite large variations in travel distances (Pelletier and Paré, 2002). Thus, in light of the present findings, we hypothesize that afferent activation of the BLA results in a synchronized and rhythmic depolarization of rhinal neurons located at different rostrocaudal levels. As a result, coincident but spatially distributed inputs of the same or different sensory modalities will become suprathreshold in the rhinal cortices. Moreover, because BLA axons
(Smith and Paré, 1994) and long-range intrinsic rhinal axons (Martina et al., 2001) do not contact inhibitory interneurons, these events should promote NMDAdependent synaptic plasticity (Bliss and Collingridge, 1993; Malenka and Nicoll, 1993; Bilkey 1996). Ultimately, the links between rhinal neurons representing different aspects of coincident sensory patterns will be reinforced (De Curtis and Paré, 2004). In this manner, the BLA could facilitate associative processes in the rhinal cortices.

\section{References}

Adolphs R, Cahill L, Schul R, Babinsky R (1997) Impaired declarative memory for emotional stimuli following bilateral amygdala damage in humans. Learn Mem 4:291-300.

Asaka Y, Griffin AL, Berry SD (2002) Reversible septal inactivation disrupts hippocampal slowwave and unit activity and impairs trace conditioning in rabbits (Oryctolagus cuniculus). Behav Neurosci 116:434-442.

Bartos M, Vida I, Jonas P (2007) Synaptic mechanisms of synchronized gamma oscillations in inhibitory interneuron networks. Nat Rev Neurosci 8:45-56.

Bilkey DK (1996) Long-term potentiation in the in vitro perirhinal cortex displays associative properties. Brain Res 733:297-300.

Bliss T, Collingridge GL (1993) A synaptic model of memory: long-term potentiation in the hippocampus. Nature 361:31-39.

Bragin A, Jandó G, Nádasdy Z, Hetke J, Wise K, Buzsáki G (1995) Gamma (40-100 Hz) oscillation in the hippocampus of the behaving rat. J Neurosci 15:47-60.

Brinley-Reed M, Mascagni F, McDonald AJ (1995) Synaptology of prefrontal projections to the basolateral amygdala: an electron microscopic in the rat. Neurosci Lett 202:45-48.

Buhl EH, Tamás G, Fisahn A (1998) Cholinergic activation and tonic excitation induce persistent gamma oscillations in mouse somatosensory cortex in vitro. J Physiol (Lond) 15:117-126.

Burwell RD, Witter MP (2002) Basic anatomy of the parahippocampal region in monkeys and rats. In: The parahippocampal region (Witter MP, Wouterlood F, eds), pp 89-105. Oxford: Oxford UP.

Buschman TJ, Miller EK (2007) Top-down versus bottom-up control of attention in the prefrontal and posterior parietal cortices. Science 315:1860-1862.

Buzsáki G, Chrobak JJ (1995) Temporal structure in spatially organized neuronal ensembles. Curr Opin Neurobiol 5:504-510.

Buzsaki G, Draguhn A (2004) Neuronal oscillations in cortical networks. Science 304:1926-1929.

Cahill L, Babinsky R, Markowitsch HJ, McGaugh JL (1995) The amygdala and emotional memory. Nature 377:295-296.

Cahill L, Haier RJ, Fallon J, Alkire MT, Tang C, Keator D, Wu J, McGaugh JL (1996) Amygdala activity at encoding correlated with long-term, free recall of emotional information. Proc Natl Acad Sci USA 93:8016-8021.

Cardin JA, Palmer LA, Contreras D (2005) Stimulus-dependent gamma $(30-50 \mathrm{~Hz})$ oscillations in simple and complex fast rhythmic bursting cells in primary visual cortex. J Neurosci 25:5339-5350.

Charpak S, Paré D, Llinás R (1995) The entorhinal cortex entrains fast CA1 hippocampal oscillations in the anaesthetized guinea-pig: role of the monosynaptic component of the perforant path. Eur J Neurosci 7:1548-1557.

Cobb SR, Buhl EH, Halasy K, Paulsen O, Somogyi P (1995) Synchronization of neuronal activity in hippocampus by individual GABAergic interneurons. Nature 378:75-78.

Cobb SR, Halasy K, Vida I, Nyiri G, Tamás G, Buhl EH, Somogyi P (1997) 
Synaptic effects of identified interneurons innervating both interneurons and pyramidal cells in the rat hippocampus. Neuroscience 79:629-648.

Collins DR, Pelletier JG, Paré D (2001) Slow and fast (gamma) neuronal oscillations in the perirhinal cortex and lateral amygdala. J Neurophysiol 85:1661-1672.

Courtemanche R, Fujii N, Graybiel AM (2003) Synchronous, focally modulated beta-band oscillations characterize local field potential activity in the striatum of awake behaving monkeys. J Neurosci 23:11741-11752.

Cunningham MO, Halliday DM, Davies CH, Traub RD, Buhl EH, Whittington MA (2004) Coexistence of gamma and high-frequency oscillations in rat medial entorhinal cortex in vitro. J Physiol (Lond) 559:347-353.

De Curtis M, Paré D (2004) The rhinal cortices: a wall of inhibition between the neocortex and the hippocampus. Prog Neurobiol 74:101-110.

Dickson CT, Biella G, De Curtis M (2003) Slow periodic events and their transition to gamma oscillations. J Neurophysiol 90:39-46.

Eckhorn R, Bauer R, Jordan W, Brosch M, Kruse W, Munk M, Reitbock HJ (1988) Coherent oscillations: a mechanism of feature linking in the visual cortex? Biol Cybern 60:121-130.

Fanselow MS, LeDoux JE (1999) Why we think plasticity underlying Pavlovian fear conditioning occurs in the basolateral amygdala. Neuron 23:229-232.

Farb CR, Ledoux JE (1999) Afferents from rat temporal cortex synapse on lateral amygdala neurons that express NMDA and AMPA receptors. Synapse 33:218-229.

Fisahn A, Pike FG, Buhl EH, Paulsen O (1998) Cholinergic induction of network oscillations at $40 \mathrm{~Hz}$ in the hippocampus in vitro. Nature 394:186-189.

Freeman WJ (1959) Distribution in time and space of prepyriform electrical activity. J Neurophysiol 22:644-665.

Galarreta W, Hestrin S (1999) A network of fast-spiking cells in the neocortex connected by electrical synapses. Nature 402:72-75.

Gibson JR, Beierlein M, Connors BW (1999) Two networks of electrically coupled inhibitory neurons in neocortex. Nature 402:75-79.

Gray CM (1999) The temporal correlation hypothesis of visual feature integration: still alive and well. Neuron 24:31-47.

Gray CM, McCormick DA (1996) Chattering cells: superficial pyramidal neurons contributing to the generation of synchronous oscillations in the visual cortex. Science 274:109-113.

Gray CM, Singer W (1989) Stimulus-specific neuronal oscillations in orientation columns of cat visual cortex. Proc Natl Acad Sci USA 86:1698-1702.

Hamann SB, Ely TD, Grafton ST, Kilts CD (1999) Amygdala activity related to enhanced memory for pleasant and aversive stimuli. Nat Neurosci 2:289-293.

Kisvárday ZF, Beaulieu C, Eysel UT (1993) Network of GABAergic large basket cells in cat visual cortex (area 18): implication for lateral disinhibition. J Comp Neurol 327:398-415.

Koch C, Crick F (1991) Understanding awareness at the neuronal level. Behav Brain Sci 14:651-726.

Krettek JE, Price JL (1977a) Projections from the amygdaloid complex to the cerebral cortex and thalamus in the rat and cat. J Comp Neurol 172:687-722.

Krettek JE, Price JL (1977b) Projections from the amygdaloid complex and adjacent olfactory structures to the entorhinal cortex and to the subiculum in the rat and cat. J Comp Neurol 172:723-752.

Lisman JE, Idiart M (1995) Storage of $7 \pm 2$ short-term memories in oscillatory subcycles. Science 267:1512-1515.

Llinás RR, Ribary U (1992) Rostrocaudal scan in human brain: a global characteristic of the $40 \mathrm{~Hz}$ response during sensory input. In: Induced rhythms in the brain (Basar E, Bullock T, eds), pp 147-154. Boston: Birkhauser.

Llinas RR, Grace AA, Yarom Y (1991) In vitro neurons in mammalian cortical layer 4 exhibit intrinsic oscillatory activity in the 10 to $50 \mathrm{~Hz}$ frequency range. Proc Natl Acad Sci USA 88:897-901.

Malenka RC, Nicoll RA (1993) NMDA-receptor-dependent synaptic plasticity: multiple forms and mechanisms. Trends Neurosci 16:521-527.

Martina M, Royer S, Paré D (2001) Propagation of neocortical inputs in the perirhinal cortex. J Neurosci 21:2878-2888.

McDonald AJ (1992) Cell types and intrinsic connections of the amygdala. In: The amygdala: neurobiological aspects of emotion, memory, and mental dysfunction (Aggleton JP, ed), pp 67-96. New York: Wiley.
McDonald AJ (1998) Cortical pathways to the mammalian amygdala. Prog Neurobiol 55:257-332.

McGaugh JL (2004) The amygdala modulates the consolidation of memories of emotionally arousing experiences. Annu Rev Neurosci 27:1-28.

Montaron MF, Bouyer JJ, Rougeul A, Buser P (1982) Ventral mesencephalic tegmentum (VMT) controls electrocortical beta rhythms and associated attentive behaviour in the cat. Behav Brain Res 6:129-145.

Muller JF, Mascagni F, McDonald AJ (2005) Coupled networks of parvalbumin-immunoreactive interneurons in the rat basolateral amygdala. J Neurosci 25:7366-7376.

Muller JF, Mascagni F, McDonald AJ (2006) Pyramidal cells of the rat basolateral amygdala: synaptology and innervation by parvalbuminimmunoreactive interneurons. J Comp Neurol 494:635-650.

Muller JF, Mascagni F, McDonald AJ (2007) Postsynaptic targets of somatostatin-containing interneurons in the rat basolateral amygdala. J Comp Neurol 500:513-529.

Murthy VN, Fetz EE (1992) Coherent 25-35 Hz oscillations in the sensorimotor cortex of awake behaving monkeys. Proc Natl Acad USA 89:5670-5674.

Palva S, Linkenkaer-Hansen K, Naatanen R, Palva JM (2005) Early neural correlates of conscious somatosensory perception. J Neurosci 25:5248-5258.

Pape HC, Narayanan RT, Smid J, Stork O, Seidenbecher T (2005) Theta activity in neurons and networks of the amygdala related to long-term fear memory. Hippocampus 15:874-880.

Parker A, Gaffan D (1998) Interaction of frontal and perirhinal cortices in visual object recognition memory in monkeys. Eur J Neurosci 10:3044-3057.

Paré D, Collins DR (2000) Neuronal correlates of fear in the lateral amygdala: multiple extracellular recordings in conscious cats. J Neurosci 20:2701-2710.

Paré D, Gaudreau H (1996) Projection cells and interneurons of the lateral and basolateral amygdala: distinct firing patterns and differential relation to theta and delta rhythms in conscious cats. J Neurosci 16:3334-3350.

Paré D, Smith Y, Paré JF (1995) Intra-amygdaloid projections of the basolateral and basomedial nuclei in the cat: Phaseolus vulgarisleucoagglutinin anterograde tracing at the light and electron microscopic level. Neuroscience 69:567-583.

Paré D, Royer S, Smith Y, Lang EJ (2003) Contextual inhibitory gating of impulse traffic in the intra-amygdaloid network. Ann NY Acad Sci 985:78-91.

Paz R, Pelletier JG, Bauer EP, Paré D (2006) Emotional enhancement of memory via amygdala-driven facilitation of rhinal interactions. Nat Neurosci 9:1321-1328.

Pelletier JG, Paré D (2002) Uniform range of conduction times from the lateral amygdala to distributed perirhinal sites. J Neurophysiol 87:1213-1221.

Phelps EA (2004) Human emotion and memory: interactions of the amygdala and hippocampal complex, Curr Opin Neurobiol 14:198-202.

Pitkänen A (2000) Connectivity of the rat amygdaloid complex. In: The amygdala: a functional analysis (Aggleton JP, ed), pp 31-115. Oxford: Oxford UP.

Pitkänen A, Kelly JL, Amaral DG (2002) Projections from the lateral, basal, and accessory basal nuclei of the amygdala to the entorhinal cortex in the macaque monkey. Hippocampus 12:186-205.

Ribary U, Ioannides AA, Singh KD, Hasson R, Bolton J, Lado F, Mogilner A, Llinás R (1991) Magnetic field tomography of coherent thalamocortical 40-Hz oscillations in humans. Proc Natl Acad Sci USA 88:11037-11041.

Richardson MP, Strnage BA, Dolan RJ (2004) Encoding of emotional memories depends on amygdala and hippocampus and their interactions. Nat Neurosci 7:278-285.

Room P, Groenewegen HJ (1986) Connections of the parahippocampal cortex in the cat. II. Subcortical afferents. J Comp Neurol 251:451-473.

Russchen FT (1982) Amygdalopetal projections in the cat. I. Cortical afferent connections. A study with retrograde and anterograde tracing techniques. J Comp Neurol 206:159-179.

Ryou JW, Cho SY, Kim HT (2001) Lesions of the entorhinal cortex impair acquisition of hippocampal-dependent trace conditioning. Neurobiol Learn Mem 75:121-127.

Sah P, Faber ESL, De Armentia ML, Power J (2003) The amygdaloid complex: anatomy and physiology. Physiol Rev 83:803-834.

Seidenbecher T, Laxmi TR, Stork O, Pape HC (2003) Amygdalar and hip- 
pocampal theta rhythm synchronization during fear memory retrieval. Science 301:846-850.

Sinfield JL, Collins DR (2006) Induction of synchronous oscillatory activity in the rat lateral amygdala in vitro is dependent on gap junction activity. Eur J Neurosci 24:3091-3095.

Singer W, Gray CM (1995) Visual feature integration and the temporal correlation hypothesis. Annu Rev Neurosci 18:555-586.

Smith Y, Paré D (1994) Intra-amygdaloid projections of the lateral nucleus in the cat: PHA-L anterograde labeling combined with post-embedding GABA and glutamate immunocytochemistry. J Comp Neurol 342:232-248.

Smith Y, Paré JF, Paré D (2000) Differential innervation of parvalbuminimmunoreactive interneurons of the basolateral amygdaloid complex by cortical and intrinsic inputs. J Comp Neurol 416:496-508.

Steriade M (1997) Synchronized activities of coupled oscillators in the cerebral cortex and thalamus at different levels of vigilance. Cereb Cortex 7:583-604.

Steriade M, CurróDossi R, Paré D, Oakson G (1991) Fast oscillations $(20-40 \mathrm{~Hz})$ in thalamocortical systems and their potentiation by mesopontine cholinergic nuclei in the cat. Proc Natl Acad Sci USA 88:4396-4400.

Steriade M, Amzica F, Contreras D (1996) Synchronization of fast (30-40 $\mathrm{Hz}$ ) spontaneous cortical rhythms during brain activation. J Neurosci 16:392-417.
Suzuki WA (1996) The anatomy, physiology and functions of the perirhinal cortex. Curr Opin Neurobiol 6:179-186.

Tamás G, Somogyi P, Buhl EH (1998) Differentially interconnected networks of GABAergic interneurons in the visual cortex of the cat. J Neurosci 18:4255-4270.

Tamás G, Buhl EH, Lörincz A, Somogyi P (2000) Proximally targeted GABAergic synapses and gap junctions synchronize cortical interneurons. Nat Neurosci 3:366-371.

Traub RD, Whittington MA, Stanford IM, Jefferys JG (1996) A mechanism for generation of long-range synchronous fast oscillations in the cortex. Nature 383:621-624.

Traub RD, Spruston N, Soltesz I, Konnerth A, Whittington MA, Jefferys J (1998) Gamma-frequency oscillations: A neuronal population phenomenon, regulated by synaptic and intrinsic cellular processes, and inducing synaptic plasticity. Prog Neurobiol 55:563-575.

Woodruff AR, Sah P (2007) Networks of parvalbumin-positive interneurons in the basolateral amygdala. J Neurosci 27:553-563.

Zola-Morgan S, Squire LR, Amaral DG (1989) Lesions of the amygdala that spare adjacent cortical regions do not impair memory or exacerbate the impairment following lesions of the hippocampal formation. J Neurosci 9:1922-1936.

Zola-Morgan S, Squire LR, Alvarez-Royo P, Clower RP (1991) Independence of memory functions and emotional behavior: separate contributions of the hippocampal formation and the amygdala. Hippocampus 1:207-220. 